\title{
Prospective Study of Intestinal Parasites in Children Hospitalized in the Pediatric Department at the Hospital in El Eldrissi (Kenitra City - Morocco)
}

\author{
Hammour Hafida \\ El Kharrim Khadija \\ Belghyti Driss
}

Laboratory of Environment and Renewable Energy, Ibn Tofail University, Faculty of Science, Kenitra, Morocco.

doi: 10.19044/esj.2017.v13n18p520 URL:http://dx.doi.org/10.19044/esj.2017.v13n18p520

\begin{abstract}
Abstrat
The aim of this study is to determine the epidemiology and prevalence of intestinal parasites in children hospitalized in the pediatric ward at the hospital El Eldrissi Kenitra during the period 2011 from the month February to May. During the study period a prevalence of $49 \%$ was recorded among the whole sample studied. The male is the most parasitized with $63 \%$. The mean age was $6.5 \pm 0.39$ year. Child aged 4 to 10 years are most affected with a frequency of $57 \%$. The majority of parasitised patients were from rural areas (64\%). The results of the parasitological analysis showed predominance of protozoa (90.6\%) compared with Helminths $(9.4 \%)$.
\end{abstract}

Keywords: Intestinal parasitosis, Protozoa, Helminth, Prevalence

\section{Introduction}

Intestinal parasitic infections are a global health problem. An estimated 3.5 billion people are infected, 450 million are ill, the majority being children and that about 155,000 die each year from causes attributable to these parasites (Alaofè et al, 2008; Bermúdez et al, 2011; Zaglool et al, 2011).

The frequency of intestinal parasites is inversely proportional to the degree of development of the countries concerned. Their strong expansion in developing countries may be associated with several factors, mainly to favorable weather conditions, lack of hygiene and sanitation and low socioeconomic and socio-cultural levels of populations (Belo et al, 2012; Bourée et al, 2007; Caravanoc et al, 2011). 
Morocco does not escape this reality, as many specific studies in certain regions of the kingdom have found the endemic nature of intestinal parasites, especially in children who are a group at risk, due to the difficulty of ensuring effective hygiene at this age, and the burden of health repercussions of intestinal parasites (malnutrition, anemia, growth retardation ...).

It is in this perspective that we have realized a prospective study in children visiting the pediatric department at the hospital in El Idrissi Kenitra over a period of four months from the month of February in May of 2011, which aims to determine the prevalence of intestinal parasites from the results of the parasitic coprology and draw up the epidemiological profile of this disease.

\section{Material and Methods}

This work consists of a prospective study of cases of infected children hospitalized in the pediatric department at the hospital in El Eldrissi Kenitra during the 2011 period from months of February in May.

The variables studied include:

The epidemiological characteristics that correspond to infected patients (age, gender), and characteristics related to the disease that is the cause, prevalence, type of parasite, parasitic association).

\section{Parasites detections methods in the stool:}

Stool specimens were from children hospitalized in the pediatric ward, are collected in sterile jars. First, we conducted a direct examination at the hospital laboratory and the samples are immediately stored in a solution of $10 \%$ formalin and transported to the laboratory environment and renewable energy of the Faculty of Sciences to Kenitra concentration examinations.We realized a macroscopic examination to Rate stool consistency and the possible existence of adult adult parasite forms. After, they wre subjected to a direct microscopic examination fresh with physiological saline and then with the Lugol. We used the technique Ritchie standardized enrichment which is recommended for research protozoa (Anécimo et al, 2012).This method consists of diluting a quantity of $2 \mathrm{~g}$ stools in $20 \mathrm{ml}$ of formalinised water to $10 \%$ then sieved through a Chinese. Was collected $2 \mathrm{ml}$ of the filtrate in a centrifuge tube in which $1 \mathrm{ml}$ of ether .One mouth of the tube and stirred to obtain a homogeneous emulsion.

Centrifuged 2 minutes 2000tr / mm .We gets four layers: a slightly yellow ethereal layer; a thick layer containing debris; a formalin layer and a residue that contains eggs; cysts and parasite larvae. The tube is suddenly empty .Using a pipette, recovering the centrifugation pellet that examines between slide and cover slip. 
The statistical methodology was based on the calculation of frequencies or averages of each variable studied that allowed us to describe the case of intestinal parasites .The variables concerning the epidemiological characteristics of patients (age, sex, origin), clinical signs (symptoms). To identify the difference between these variables, we used the chi-square test $(\chi 2)$ with a risk of error of 0.05 . A test is retained as being from a significant level $\mathrm{p}<0.05$.

\section{Results}

During the study period, a total of 138 children received a parasitological stool analysis, detecting parasites in stool was positive in 67 children, which corresponds to a prevalence of $49 \%$ among the entire sample studied. The male is the most parasitized compared to women with a frequency of $63 \%$, the two chi test at $5 \%$, showed a highly significant link based male (chi-square $=12.78, \mathrm{p}<0.001$ ) (Figure 1 ). The majority of patients were from rural areas $(64 \%)$.

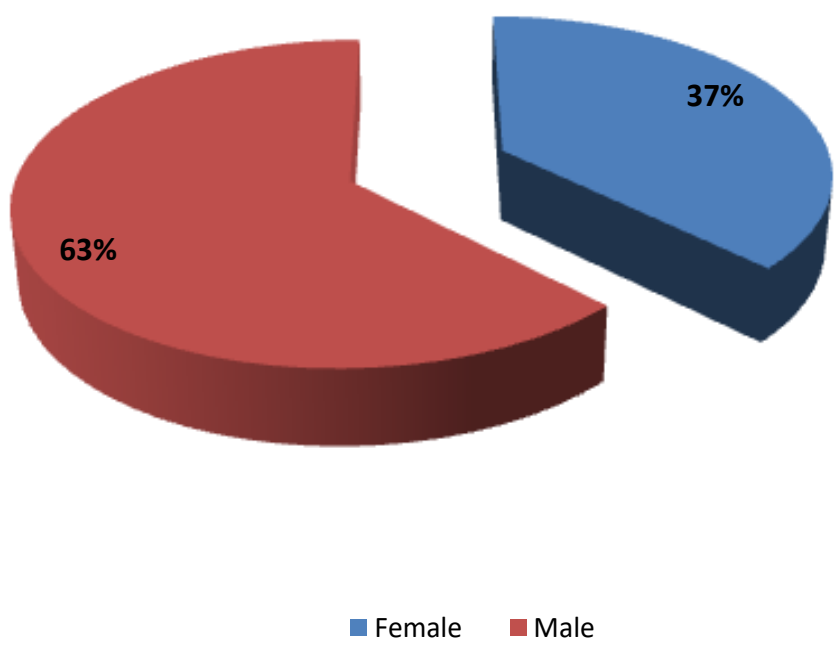

Figure 1: Distribution of parasitised children according to sex.

The mean age was $6.5 \pm 0,39 \mathrm{an}$, with extremities of between one to 12 years. According to the results of Figure 2, we find that the most affected age group is children aged 4 to 10 years with a frequency of $57 \%$, followed by infants $(25 \%)$ and adolescents $(18 \%)$ (Chi-square $=47.4 ; \mathrm{p}<0.001)$ (Figure 2) 


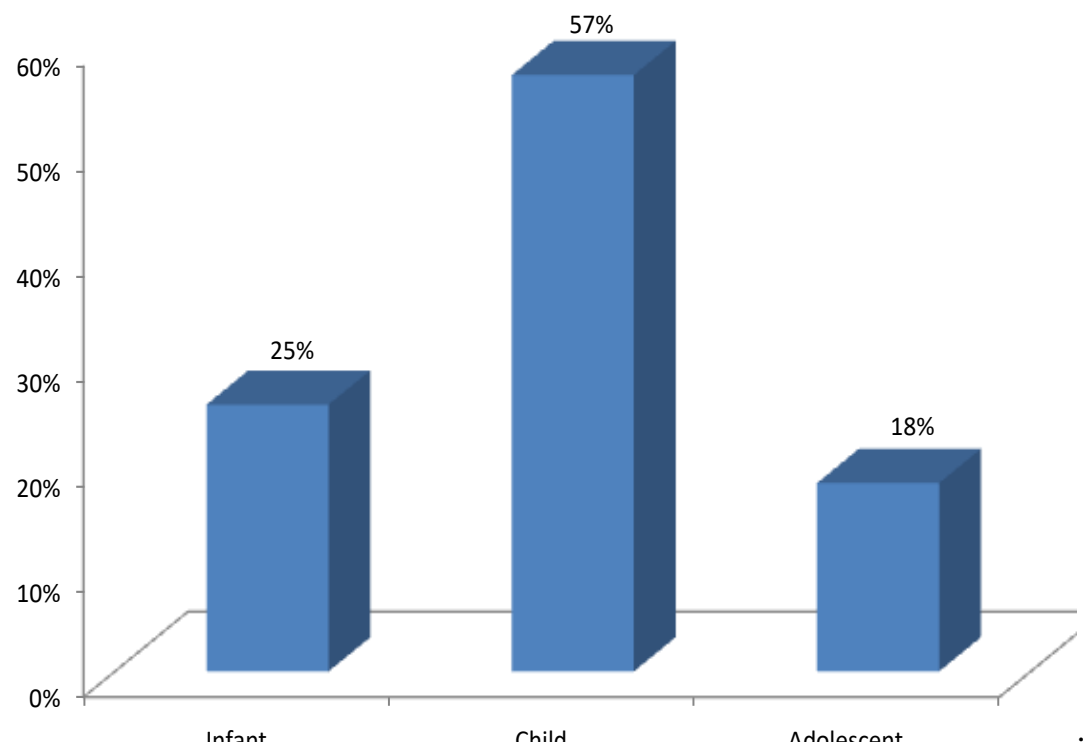

Figure 2: Distribution of children parasitised by the age groups.

Infant: [1-4[Year +Child: [4-11[Year; Adolescent: [11-16[Year

The prevalence parasitized children was studied for each age group (Table 1), which allows us to show that the category of 4 to 11 years had the highest prevalence.

Table 1: Prevalence of parasitism according to the age groups of children

Group age(Year) $\quad[1-4[\quad[4-11[\quad[11-16[$

\begin{tabular}{cccc}
\hline $\begin{array}{c}\text { Number of children } \\
\text { examined }\end{array}$ & 48 & 70 & 20 \\
$\begin{array}{c}\text { Number of children } \\
\text { parasitised }\end{array}$ & 17 & 38 & 12 \\
\begin{tabular}{c} 
parasitological prevalence \\
\hline
\end{tabular} & $12 \%$ & $28 \%$ & $9 \%$ \\
\hline
\end{tabular}

According to the results of Table 2, twelve species were detected. They are in order of decreasing frequency. The most frequently observed were generally: Blastocystis hominis (30.2\%), Entamoeba coli (25.6\%), Giardia intestinalis (17.4\%) and Entamoeba histolytica (10.5\%). We have identified twelve associations parasitic species Entamoeba coli + Blastocystis hominis is the most observed association with 26, 09\% (Table 3 ). The results of Figure 3 showed that patients near inhabitants of discharge are most infected with a $45 \%$ frequency (Figure 3).

Table 2 : Different parasite species identified.

$\begin{array}{lll}\text { Parasite species } & \mathrm{n} & \%\end{array}$




\begin{tabular}{ccc}
\hline Blastocystis hominis & 26 & 30,2 \\
Entamoeba coli & 22 & 25,6 \\
Giardia intestinalis & 15 & 17,4 \\
Entamoeba histolytica & 10 & 11,6 \\
Chilomastix mesnili & 3 & 3,5 \\
Ascaris lumbricoïdes & 3 & 3,5 \\
Trichirus trichiura & 2 & 2,3 \\
Entamoeba minuta & 2 & 2,3 \\
Enterobius vermicularis & 2 & 2,4 \\
Hymenolepis nana & 1 & 1,2 \\
Total & 86 & 100 \\
\hline
\end{tabular}

Table 3 : Parasitic Associations

\begin{tabular}{ccc}
\hline Parasite species & $\mathrm{n}$ & $\%$ \\
\hline Entamoeba coli + Blastocystis hominis & 6 & 26,09 \\
Blastocystis hominis + Giardia intestinalis & 3 & 13,04 \\
Entamoeba histolytica + Blastocystis hominis & 3 & 13,04 \\
Ascaris lumbricoüdes + Blastocystis hominis & 2 & 8,70 \\
Entamoeba coli + Giardia intestinalis & 2 & 8,70 \\
Entamoeba histolytica + Chilomastix mesnili & 2 & 8,70 \\
Entamoeba minuta + Blastocystis hominis + & 1 & 4,35 \\
Entamoeba coli & & \\
Entamoeba coli + Blastocystis hominis + & 1 & 4,35 \\
Chilomastix mesnili & & \\
Entamoeba coli + Giardia intestinalis + Ascaris & 1 & 4,35 \\
lumbricoïdes + Trichirus trichiura & & \\
Entamoeba histolytica + Trichirus trichiura & 1 & 4,35 \\
Giardia intestinalis + Enterobius vermicularis & 1 & 4,35 \\
Total & 23 & 100 \\
\hline
\end{tabular}




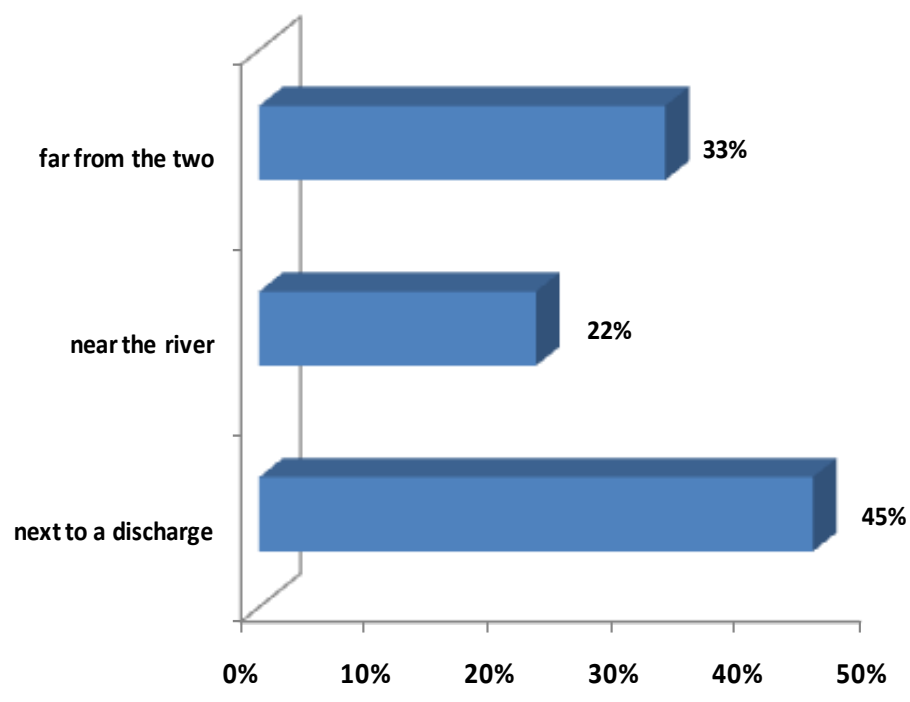

Figure 3: The influence of the location of the habitat on parasitic portage.

\section{Discussion}

The aim of this work is to determine the prevalence of intestinal parasites, as well as the factors influencing the parasite carriage in hospitalized children. The rates of parasitism were recovered $49 \%$. In other studies, it is of the order of $68.1 \%$ (Elqaj et al, 2009) and $52.7 \%$ of El Guamri (El Guamri, 2010), this can be explained by the influence of the origin of the majority of patients was of rural origin with a frequency of $64 \%$.

The males are the most affected by parasitism (63\%), the results could be explained by the done that boys are more exposed to fecal peril and in contact with dirty hands, because of their behavior (games between boys and intense contact with the ground). Statistically, a highly significant difference was recorded for sex ( $p<0.001$ ), results are contradictory to those reported by Ayadi, and Bonchai Agbolade(Ayadi et al, 1991; Boonchai et al, 2007; Agbolade et al, 2007).

The mean age was $6.5 \pm 0.39$ in the most represented age group is children aged 4 to 10 years with a frequency of $57 \%$ school age when life in collectivity, promiscuity, the contact with the ground and the precarious food and fecal contamination promote hygiene.

The decrease appears then the adolescent age [11-16 [years when children learn the basics of health education and acquire good hygiene. This result is similar with other work where children are infected at an early age and even before the age of one year, but the peak of parasitism was between 4 and 6 years (Ayadi et al, 1991). In the literature the influence of the age 
factor is significantly demonstrated by the work of Mostafi (Mostafi et al, 2010), which is consistent with our results.

The parasitological stool analysis by the method of Ritchie, has allowed us to identify two groups of parasites with a predominance of protozoa (90.6\%) of which $30.2 \%$ Blastocystis hominis with Entamoeba coli with 25.6\%, Giardia intestinalis (17.4\%) Entamoeba histolytica (11.6\%), Entamoeba minuta (2.3\%), Chilomastix mesnili $(3.5 \%)$ and helminths $(9.4$ $\%$ ) including Ascaris lumbricoïdes (3.5\%), Trichirus trichiura (2.3\%), Enterobius vermicularis(2.4\%), Pinworm, Hymenolepis nana with 1.2 for each of them, which is similar with the study of Benouis(Benouis et al, 2013) and discordant to those recorded at the CHU of Guadeloupe(Nicols et al, 2003) with $72.3 \%$ and $27.7 \%$ of Helminths of Protozoa.

\section{Conclusion}

The prevalence of intestinal parasitism is quite high in the examined population. Several parasite species are criminalized. Unsanitary living conditions and poor hygiene promote endemicity and perpetuation of the transmission. The best way to fight against this scourge is prevention, hygiene and individual and collective awareness.

\section{References:}

1. Alaofè H, Zee J, Dossa R, O’Brien H. Intestinal parasitic infections in adolescent girls from two boarding schools in southern Benin . Transactions of the Royal Society of Tropical Medicine and Hygiene, 2008; 102:653-661.

2. Bermúdez $\mathrm{M}$, Hernández $\mathrm{M}$, Llaque $\mathrm{G}$,et al .Frecuencia de Blastocystis hominis y factores de riesgo en escolares de la parroquia el cuji. Estado lara. Salud, Arte y Cuidado, 2011; 4(2):13-19.

3. Zaglool D, Khodari Y, Zohair J, et al .Prevalence of intestinal parasites among patients of Al-Noor specialist hospital, Makkah, Saudi Arabia. Oman Medical Journal, 2011; 26(3): 182-185.

4. Belo V, de Oliveira R, Fernandes P, Warlley B, et al. Factors associated with intestinal parasitosis in a population of children and adolescents. Rev Paul Pediatr, 2012;30(2):195-201.

5. Bourée P, Bisaro F. Diarrhées parasitaires. La Presse Médicale, April 2007; 36(4): 706- 716.

6. Caravanoc L, Coppolac M, Cringolib G. Intestinal parasitic infections and malnutrition amongst first-cycle primary schoolchildren in Adama, Ethiopia . Afr J Prm Health Care Fam Med, 2011; 3(1):1985 p.

7. Anécimo R, Tonani K, Fregonesi B, Mariano A, Ferrassino M, Trevilato $\mathrm{T}$, et al. Adaptation of Ritchie's Method for Parasites 
Diagnosing with Minimization of Chemical Products. Interdiscip Perspect Infect Dis. 2012; 2012:409757 pubmed publishers

8. Mouna Elqaj, Driss Belghyti , Ahmed Ahami , Hamid Loutfi, Khadija El Kharrim, Youness Taboz. Prévalence des parasitoses intestinales chez les écoliers en milieu rural Kenitra - Maroc. World Journal of Biological Research. ISSN : 1994-5108.2009.

9. El Guamri Y., 2010. Étude de l'impact des eaux usées sur l'environnement et enquêtes épidémiologiques du parasitisme intestinal dans la région du Gharb (Kénitra - Maroc). Thèse de Doctorat. Fac. Sci. Kénitra. Maroc.

10. Ayadi A, Mahfoudh A, Mahjoubi F.Parasitoses intestinales chez l'enfant bilan de 2 ans dans le centre Hospitalo Universitaire de Sfax. Médecine d'Afrique Noire 1991; 38(8/9):557-560

11. Boonchai W, Apichai S, Oralak S. Intestinal parasitic infections among pre-school children in Sangkhlaburi, THAILAND .Am. J. trop. Med. Hyg. 2007; 76(2):345-350.

12. Agbolade OM,Agu NC, Adesanya OO. ntestinal helminthiases and schistosomiasis among school children in an urban .Center and some rural communities in southwest Nigeria. Korean Journal of Parasitology.September 2007; 3:233-238.

13. Jaouad Mostafi, Driss Belghyti, Mohamed El Kostali, Naima Fatimi, Said Oulkheir, Youness Taboz, Khalid Arouya. Prévalence des parasitoses intestinales chez les enfants adressés pour coprologie parasitaire à l'hôpital Moulay Abdellah de Salé (Maroc). vol.4 Issue 1, ISPROMS ISSN : 1994-5108, 2010.

14. Benouis.A, Bekkouche, Z. Benmanso.A.Epidemiological study of human intestinal parasitosis in the Hospital of Oran (Algeria) .International Journal of Innovation and Applied Studies. Vol. 2 No: 2028-93, 2013.

15. M. Nicols, JM. Perez, B. Carme, "Diagnostic des parasitoses intestinales au CHU de la Guadeloupe : évolution de 1991 à 2003". Bull. Soc. Pathol. Exot., vol. 99, no. 4, pp. 254-247, 2006. 